Revista de Filosofía

Volumen 71 (2015) 113-125

\title{
HISTORIA Y FILOSOFÍA. SOBRE EL CARÁCTER CONTINGENTE O NECESARIO DE LA HISTORIA PARA LA FILOSOFÍA
}

\author{
Vicente Raga Rosaleny \\ Universidad de Antioquia \\ Medellín, Colombia \\ vicente.raga@udea.edu.co
}

\begin{abstract}
Resumen / Abstract
¿Es necesaria la historia para la filosofía? En tiempos de especialización disciplinaria como los actuales, parecería ésta una pregunta obvia y la respuesta, casi innecesaria. Sin embargo, lo cierto es que en la actualidad asistimos a un debate y a una fragmentación del campo filosófico en relación precisamente con el carácter contingente o necesario de la historia para la filosofía.

Por ello, tomando como modelos de relación con la historia tanto el ámbito del arte como el de la ciencia, en este artículo trataremos de elucidar qué papel puede cumplir la historia en el ámbito filosófico. Frente a los defensores de la historia como un elemento esencial de la filosofía, pero también distanciándonos de quienes reservan un lugar secundario a la historia en nuestra disciplina, plantearemos una tercera vía.
\end{abstract}

PALABRAS Clave: filosofía, historia, historia de la filosofía, realismo, relativismo.

HISTORY AND PHILOSOPHY. ON THE CONTINGENT OR NECESSARY ROLE OF HISTORY TO PHILOSOPHY

Is it History necessary to Philosophy? In times of specialization,this would seem an obvious question and the response, almost unnecessary. However, the truth is that today we are witnessing a debate and a fragmentation of the philosophical field precisely around the question of the necessary or contingent character of History to Philosophy. Therefore, taking models of relationship with history both from the fields of Art and Science, in this article we will try to elucidate what role can meet the History in the philosophical field. Against advocates of History as an essential element of Philosophy, but also distancing us from who reserve a secondary place to History in our discipline, we would defend a third way.

KEY WORDS: philosophy, history, history of philosophy, realism, relativism.

R⿴囗十 ¿Es necesaria la historia para la filosofía? ¿Cumple la historia de la filosofía algún papel esencial, o al menos no contingente, en la propia disciplina? En tiempos de especialización disciplinaria como los actuales, parecería ésta una pregunta obvia y la respuesta, casi innecesaria. Sin embargo, lo bien cierto es que en la actualidad asistimos a un debate y a una fragmentación del campo filosófico en relación precisamente con el carácter contingente o necesario de la historia para la filosofía. 
Como decimos, pues, la pregunta por la relevancia, disparidad o complementariedad entre filosofía e historia mantiene de algún modo dividida nuestra disciplina, y lo que parecería un mero tópico se convierte en una disputa de difícil resolución. Y así, hay posiciones radicales en la actualidad, opuestas a que la historia tenga un espacio en el estudio y práctica de la filosofía, como la que suele citarse de Harman (que en la puerta de su despacho, según Bernard Williams, tenía una nota con un eslogan tajante: "Di no a la historia de la filosofía") ${ }^{1}$, o la de Quine, y su broma sobre la distinción entre dos tipos de personas interesadas en la filosofía, las interesadas en la propia filosofía y las que lo estarían tan solo en su historia (MacIntyre 1990, 59).

Pero tales objeciones no serían sino un reflejo de otras muy semejantes, mantenidas en el pasado por autores tan relevantes para la historia de la filosofía como Descartes o Hume. Según ciertas lecturas, la voluntad "ilustrada" de este último, con su concomitante rechazo de la autoridad tradicional, habría quedado plasmada en actitudes como la exhibida al final de la Investigación sobre el conocimiento humano, donde invitaba a quemar los volúmenes de teología o metafísica escolástica, otorgando a la razón, abstracta o experimental, toda la capacidad a la hora de indagar sobre los problemas fundamentales del conocimiento (Hume 2001, 209). Y lo mismo cabría decir clásicamente de Descartes, quien desde ciertas interpretaciones se habría opuesto a la enseñanza de la historia en favor del conocimiento personal, a través del uso de la propia razón y de la acumulación de experiencias².

Evidentemente, también podrían encontrarse posiciones radicales del lado contrario, tanto presentes (en autores como Gadamer o Ricoeur, por ejemplo), como pasadas. Aunque los defensores de la historicidad de la filosofía tienen, sin duda, a su representante más destacado bajo cualquier interpretación en la figura de Hegel. Es en este pensador en donde la búsqueda de la verdad, que caracterizaría al filosofar desde su perspectiva, se entendería como necesariamente enmarcada en un proceso histórico, que condicionaría incluso los objetivos y métodos de tal indagación. La filosofía, que sería histórica por su propia naturaleza cobraría forma en el mismo decurso temporal en el que se formaría la verdad que la disciplina filosófica desea alcanzar (Hegel 2010, 112).

Igualmente podrían indicarse posiciones más moderadas, tanto en defensa de la importancia de la historia para la filosofía, como en sentido contrario. Y así, autores como Taylor o Williams (Taylor 1990, 32; Williams 2002, 7ss.), han afirmado la necesidad de conocer los problemas, métodos y conceptos del pasado, tanto en sus orígenes, como en su posterior desarrollo. Desde esta perspectiva, no se puede evitar

$1 \quad$ Entre otras partes, citado en Williams 2011, 226.

2 Como indicaría de manera muy provocadora en Descartes 1987, 7ss., donde dice derivar de las enseñanzas de los antiguos tan solo una gran ignorancia, o en Descartes 2005, 129ss., en donde invitaría a hacer una tabula rasa con el pasado escolástico y con el mundo antiguo en general. El ejemplo de Hume quizá no sea tan claro como ilustración de esa crítica a la complementariedad entre historia y filosofía, aunque sí, creemos, ilumina el rechazo a la tradición que también caracterizaría a Descartes, desde ciertas interpretaciones. 
un cierto dogmatismo si no se atiende correctamente a ese pasado que condiciona nuestra actualidad filosófica. Olvidar el pasado implicaría el riesgo de incurrir en los mismos errores que la tradición ha ido develando: quien no conoce su historia estaría condenado a repetirla.

De otro lado, autores como Rabossi, por mencionar alguien de un contexto más cercano, o González y Stigol ${ }^{3}$, entre muchos otros, defenderían posiciones más cercanas a la tesis de la filosofía como una historia de los problemas, rechazando que tenga en realidad una larga historia, como disciplina. Tales autores abogarían por un recurso pragmático a la historia de tan "reciente" ámbito del saber (González y Stigol $2012,6,11)$. No se opondrían así a la enseñanza de la historia en la filosofía, pero sí a la idea de su vinculación necesaria con nuestra disciplina.

Así, aunque a menudo se ha dicho que el debate entre historia y filosofía entraría dentro de un ámbito de discusión más amplio entre dos supuestas corrientes filosóficas contrapuestas, la analítica y la continental, este complejo panorama pone de manifiesto que tal reducción resulte poco plausible ${ }^{4}$. De hecho, tal distinción ha generado muchas polémicas y resulta muy difícil establecer con claridad los criterios que permitan distinguir entre la supuesta filosofía "continental" (que en muchos casos se identifica tout court con la escuela hermenéutica) y la "analítica", y no sería el de la actitud frente a la historia uno de los puntos menores de tal disenso (autores como el mencionado Bernard Williams se encuadrarían, por ejemplo, dentro de la supuesta lista de autores analíticos, pero al mismo tiempo éste sería un claro defensor de la importancia de la historia para la filosofía, frente al tópico rechazo de la misma que se atribuye a tal corriente).

\section{1. ¿Ciencia o arte?}

Así pues, instalados en el debate propiamente dicho, podemos empezar señalando que, frente a los opositores radicales, e incluso frente a los moderados, que entienden que la historia cumple un papel secundario o matizado en la filosofía, parece complicado encontrar una disciplina que mantenga una relación tan estrecha con la historia como ésta. Si acudimos al plan de estudios de cualquier otra carrera universitaria, al pensum de cualquier otro programa, difícilmente encontraremos alguno en el que la propia historia tenga tanto peso.

3 De estas autoras tomamos la referencia de Rabossi y discutimos con ellas a lo largo de este texto, sobre todo siguiendo su González y Stigol 2012.

4 Por ejemplo, la lleva a cabo de manera especial en nuestro ámbito lingüístico Jaran 2011, en un artículo que pese al desacuerdo de fondo que mantenemos con él, nos ha resultado realmente iluminador por lo que respecta a esta cuestión. 
Ciertamente, el contraste puede parecer más claro en el caso de las disciplinas científicas, asociadas a las ciencias naturales y aplicadas, que en el de las humanidades, o en otro plano, en el caso del ámbito artístico. En ese sentido podría distinguirse ${ }^{5}$ entre el modo de relacionarse de la "ciencia" y del "arte" con su historia, para establecer posibles comparaciones, vínculos y diferencias, que permitan despejar las incógnitas por lo que respecta al estatuto de la historia en el ámbito filosófico.

Siguiendo esta propuesta podría decirse que aunque las "ciencias naturales" tienen historia, ésta no les resulta interesante o importante por sí misma, como fuente de conocimiento. Los biólogos saben de Linneo, pero no se les pide que lean su Systema naturae, dado que en muchos aspectos podría ser un texto ya superado en la actualidad, por los nuevos descubrimientos y teorías.

Por decirlo mediante una formulación elegante, en los términos del ya mencionado Bernard Williams, la ciencia tiene una "historia vindicatoria" (Williams 2000, 486), esto es, que en su discurrir temporal, las teorías más recientes no solo se justificarían a sí mismas, sino que también aclararían las concepciones de las anteriores teorías y justifican el paso de unas a otras. De este modo, tanto los partidarios de las concepciones antiguas como los de las teorías modernas se han de ver obligados a reconocer en tal transición un progreso. Y tal progreso iría dejando atrás, como elementos sin valor cognoscitivo, aquellas etapas que precedieron a las actuales en cualquier campo científico.

En contraste con las ciencias, las artes parecen guardar con su historia una relación muy diferente. Cada etapa de la historia del arte no deja paso a la siguiente cuando queda anticuada, los diferentes momentos no se suceden con una suerte de progreso similar al científico. Frente a lo que sucede con Linneo o Lamarck, en el ámbito de la biología, o con Newton en el de la física, la introducción del monólogo interior en la novela contemporánea no puede entenderse, por ejemplo, sin el contraste que ello supone con el narrador omnisciente de la gran novela decimonónica. E igualmente, la ruptura con la perspectiva pictórica durante las vanguardias se explica al atender a la importancia de la misma del Renacimiento en adelante.

Esto es, que aunque el artista no es un historiador, la relación con su propia historia no es casual o superficial. Aunque no cuente con un conocimiento histórico completamente preciso, necesariamente ha de remitirse a su marco histórico en el momento de crear una obra, ha de ubicarse por respecto a su tradición, y las innovaciones que introduce solo cobran sentido al superponerlas al trasfondo histórico en el que se sitúa, al ubicarlo en su contexto temporal. Aún más, precisamente la existencia de un canon artístico o de obras clásicas, que uno puede venerar o criticar, pone de manifiesto esa idea de la importancia de la historia en el caso del arte.

En esa misma línea, quienes realizan estas distinciones con el propósito de dilucidar el modelo de relación con la historia más adecuado para la filosofía (como el ya mencionado Jaran 2011, 171ss.), suelen fijar la diferencia entre ambas áreas de

5 Como productivamente hace el mencionado Jaran 2011. 
la actividad humana en la diferente valoración o peso de la noción de validez, y en suma, de acuerdo al papel que juega la verdad en cada una de ellas. En relación con esta idea, toda pretensión de validez, todo vínculo con la "objetividad", quedaría del lado de la ciencia, mientras que del lado del arte la verdad se perdería en los extremos de la subjetividad y el relativismo histórico y cultural.

Sin embargo, no podemos coincidir plenamente con este diagnóstico y su subsiguiente distinción. Es decir, que puede ser cierto que tan solo el ámbito del arte establezca una relación dialógica con su devenir histórico, y que la ciencia tenga un vínculo real con su pasado, pero sin peso específico en su presente, salvo en términos de validez. Esto es, que parece factible sostener que al científico le interesa su pasado en tanto que conocimiento aún vigente, en aquello que aún tienen de válido las formulaciones científicas del pasado, pero de ello no se sigue que el arte no guarde relación alguna con el mundo o que no tenga aspiraciones de veracidad y de sentido que escapen a una suerte de relativismo lato.

El arte, como indica, entre otros, el profesor Jusdanis, es a la vez una entidad autónoma y una convención social, y se mueve en el espacio que se abre entre la ficción y la realidad (Jusdanis 2014, 95). Ciertamente, el arte no dispone de un mundo "objetivo" al que adecuarse, que sirva de piedra de toque de sus realizaciones, pero la entrada consciente en un mundo inventado es una experiencia valiosa, debido al potencial parabático de la literatura:

A este ahondar las fronteras lo denomino el potencial parabático de la literatura, un término que adapto de esa parte de la comedia de Aristófanes en la que los miembros del coro dan un paso adelante, se quitan las máscaras y se dirigen a la audiencia como ciudadanos, en vez de como actores en el escenario.

Este papel doble del coro, como intérpretes y como miembros de la "polis", pone de relieve la capacidad dual del arte de proporcionar placer y tener un propósito social al mismo tiempo. Por un lado, disfrutamos y nos entusiasmamos al adentrarnos en un mundo ilusorio. Pero, por otro, desde este universo de ficción también podemos volver la mirada al mundo real para criticarlo, ver alternativas o intentar transformarlo. En resumen, aunque nos gusta el arte por su potencial creativo, hay algo más allá del deleite personal en nuestra atracción que es de carácter político. Esta función parabática subraya la relación estructural que la literatura mantiene con la realidad (Jusdanis 2014, 16).

Es decir, que aunque en el ámbito artístico quizá nada sea válido o inválido en sí mismo, sí puede haber pretensiones de sinceridad, intentos de resultar preciso, determinados valores asociados a la veracidad que no pueden dejarse de lado, y que no permiten reducir la discusión entre ambos modelos de relación con la historia a una cuestión de verdad y ficción, de objetivismo o subjetivismo sin matices.

Más aún, tal discusión resulta relevante, en la medida en que el tema de nuestro texto no gira en torno a la relación de la ciencia o del arte con la historia, sino sobre el vínculo que existe entre ésta y la filosofía. Precisamente explicitar algunos aspectos derivados de una mala comprensión de los dos modelos, o al menos de una cierta interpretación tópica de los mismos, nos permitirá rastrear mejor la cuestión del papel 
de la historia en la disciplina filosófica, dado que ambos parecen tener semejanzas y diferencias con la tradición de nuestro ámbito.

\section{Historia y filosofía}

Igual que sucede en el arte, muchos pensadores consideran que la historia es la mejor maestra para el filósofo, que el trabajo del pensamiento tan solo puede aprenderse en las aulas de la historia. Al leer a Platón o a Descartes, hacemos algo que el biólogo no puede hacer leyendo a Lamarck, y que el escritor sí logra cuando lee a Proust o a Cervantes: aprender un oficio. Además, también en la filosofía existen obras "canónicas" y autores clásicos, y siempre que se propone alguna tesis nueva se hace desde determinada perspectiva o tradición.

Sin embargo, como plantean González y Stigol, no es claro que tal identificación entre historia y filosofía sea una cuestión normativa antes que contingente (González y Stigol 2012,4). Después de todo quizá estemos incurriendo en una falacia, mezclando lo que es una cuestión de hecho, que en las aulas de filosofía se imparte historia de manera destacada, como en el arte se hace referencia a la tradición de manera habitual, con un deber: que, porque muchos filósofos conozcan o hayan conocido la historia de la filosofía, debemos conocerla para poder filosofar.

Frente a esta tesis, que aboga por la necesidad de la historia, la propuesta de estas autoras y de muchos otros pensadores, siguiendo un modelo más cercano al de la ciencia, plantearía el carácter contingente de tal vínculo. En consonancia con la idea de que a diferencia de lo que sucede en la esfera del arte, la filosofía tiene una pretensión de verdad que la aproxima a las disciplinas científicas, ésta se alejaría del ámbito artístico y de sus compromisos con la historia. Tendríamos así una serie de propuestas que sin rechazar la historicidad abogarían por una distancia respecto de los textos, una menor atención a los autores y a la génesis y desarrollo de sus conceptos.

Desde esta perspectiva, el conocimiento de la historia no sería imprescindible, aunque sí podría resultar recomendable, siempre que no se entendiera su contribución como un diálogo con textos y contextos de autores alejados en el pasado, y pertenecientes a sistemas conceptuales e imágenes del mundo en cierta medida diversas de la nuestra. En su lugar, cabría entender tal relación en los términos de un debate actual entre coetáneos, con problemas a los que responder desde el aquí y el ahora, a los que la historia podría contribuir con soluciones y propuestas (o con puntos de vista errados, pero que igualmente ayudarían a iluminar el problema actual).

Tal concepción de la historia de la filosofía, con esa lectura de los pensadores que nos precedieron, y de los que nos separa la corriente temporal a veces con siglos de intervalo, como si fuesen nuestros coetáneos (Engel 1999, 453) introduciría pues diversas exigencias para que tal diálogo fuese posible. En lugar de ensayar una reconstrucción contextual de los textos del filósofo de tiempos pretéritos a la luz de la historia, el pensador se apropiaría del texto tratando de dilucidar cuáles serían los problemas 
que allí se ventilan y las respuestas que se proponen. La solidez de los argumentos esgrimidos y su plausibilidad se valorarían con arreglo a criterios actuales, haciendo uso de nuestros parámetros. En ese sentido, no importaría tanto lo que hubiera podido decir el filósofo clásico, sino, en mayor medida, lo que hubiera debido argumentar para estar en lo cierto.

Claramente, esta propuesta de relación entre historia y filosofía tendría también sus orígenes, su propia historia, en concreto la hipótesis de la existencia de una "historia de los problemas" habría sido la respuesta neokantiana a la tesis idealista de un Hegel que entendía que cada etapa de la historia de la filosofía llevaba consigo la asunción de nuevos problemas, cada vez más complejos. En contraste con esto, para los neokantianos, nuestra historia estaría compuesta de una serie de soluciones dadas a problemas siempre idénticos (Windelband 1980, iv).

Sin embargo, para los defensores actuales de tal posición no sería necesario asumir la implausible tesis de una perennidad de los problemas filosóficos para apoyar una propuesta como la de la "historia de los problemas" que difundió Passmore (Passmore 1965, 27). Sin que haga falta defender que hay una identidad problemática en el curso del tiempo, que no atendería a la pluralidad temporal y espacial, cultural y lingüística de los contextos, cabría la posibilidad de aducir que la historia de la filosofía debería tener como su objeto propio los problemas filosóficos. Problemas dictados, claro está, por la presión de las circunstancias y, desde nuestra perspectiva, imbuidos siempre de actualidad.

Los valedores de tal concepción, pues, asumirían que para entender y asimilar al quehacer filosófico actual cualquier teoría del pasado tendría que elucidarse el problema al que pretendía responder. En esa dirección, cabría llevar a cabo una "reconstrucción racional" de los argumentos y puntos de vista de los filósofos desaparecidos, en nuestros propios términos, para poder evaluar e interpretar a esos "pares" con los que nos encontraríamos en la actualidad sin importar cuán distantes en el tiempo se ubicasen y la lejanía de los contextos a los que respondiesen.

Es evidente que tal perspectiva de la historia prestaría escasa atención a lo que efectivamente dijeron los filósofos, importando tan solo la pertinencia de sus tesis para los problemas actuales, a cuya solución contribuirían en uno u otro sentido. Siendo así las cosas, cualquier concepción que concediera mayor relevancia a la historia, al cuidadoso estudio del contexto y a su contribución para la reconstrucción del pensamiento efectivo de un pensador del pasado, se enfrentaría al rechazo y la oposición de esta propuesta, que se concibe como la más propiamente filosófica, frente a aproximaciones de corte más histórico o historicista.

Pero, si los problemas no se mantienen incólumes en el curso del tiempo, si no son perennes, sino que van variando y cambian de contexto en contexto, ¿no resultaría necesario conocer un tanto mejor éste para realizar la reconstrucción racional propuesta? Una lectura contextual no tendría que ser necesariamente un ejercicio entendido como un fin en sí mismo, animado por un simple deseo de erudición. Antes bien, podría sostenerse que tal atención tendría como finalidad, en el caso de la historia de la filosofía, la búsqueda de una mejor comprensión de los textos, de sus articulaciones 
internas y de las implicaciones filosóficas y culturales que ponen en juego. Asimismo, podría ser quizá un error concebir la lectura contextual como una tentativa de reducir el texto a su contexto, como si éste pudiera reabsorberlo, anulando o disminuyendo su especificidad. El interés principal de una lectura contextual no se limitaría así a la búsqueda de influencias reales o eventuales, sino que tendría un sentido principalmente explicativo, buscaría ofrecer una comprensión histórica de la génesis y función de los textos en relación con sus contextos (Paganini 2008, 334-335).

Por último, como ha sugerido Quentin Skinner, el método contextual permitiría responder a una cuestión que no puede abordarse ni formularse en una simple lectura interna. Y es que no solo podría ser importante lo que el autor está diciendo en su texto, sino también aquello que su texto lleva a cabo, en el momento de escribirse, las posiciones que toma en relación con los interlocutores que escoge, y las actividades intelectuales en que va a implicarse en relación con su cultura y textos de referencia (Skinner 1969, 49).

Sin embargo, es claro que tal propuesta no contaría con la aquiescencia de los que consideran que la historia ha de jugar un papel secundario y opcional en la filosofía. Desde esta posición se ha de plantear la duda respecto a las posibilidades de realizar tales reconstrucciones históricas. ¿Acaso podemos desprendernos tan fácilmente de nuestros propios puntos de vista y dialogar con nuestros antepasados en sus propios términos? Si para comprender una obra hemos de considerarla como una maniobra dialéctica, en el seno de una discusión en la que nosotros nos introduciríamos, cabría la posibilidad de preguntarse si la idea de abandonar nuestros propios marcos teóricos, para introducirnos en los ajenos, no está de antemano condenada al fracaso.

De nuevo nos encontramos ante una antinomia semejante a la que observábamos al atender a las relaciones con la historia que manifestaban ciencia y arte. Desde una perspectiva tópica, la ciencia no tendría interés en la historia, sino en tanto que muestra su validez en la resolución actual de problemas, en la búsqueda de una verdad en términos absolutos. Por su parte, el arte se interesaría de manera no casual en su propia tradición, en la medida que establece diálogos con ella, aquejados quizá del peligro del anacronismo, de un lado, y del relativismo, de otro, aunque sin presiones por lo que respecta a la verdad, aceptando la multiplicidad de contextos y propuestas, sin que en sus búsquedas estéticas se anhele ninguna resolución definitiva. Entre tales cuernos del dilema parecería asentarse el debate entre los defensores de la "historia de los problemas" y los valedores de la reconstrucción contextual.

\section{3. ¿Filosofía o filosofías?}

Cambiemos por un momento de contexto y atendamos a una cuestión distinta aunque directamente relacionada. Desde cierta perspectiva, epistemológica, cabría decir que el conocimiento es el intento de tender un puente que una la perspectiva interna, o subjetiva, con la externa, u objetiva. Pero la posibilidad de trazar ese enlace está condicionada por el modo en que se entienda lo objetivo y lo subjetivo. 
Existe una concepción, de raigambre casi podríamos decir cotidiana, que plantea que lo que hay en el mundo, lo externo, es independiente de lo que nosotros pensamos que hay, lo interno. Si esta suerte de realismo ingenuo podría entenderse que respeta ciertas limitaciones, lo que hay es en algún sentido independiente de lo que pensamos que hay, su versión filosófica, el realismo metafísico ${ }^{6}$, se extendería hasta decir que tal distinción es completa: lo que hay es totalmente independiente de lo que pensamos que hay.

Sin embargo, un resultado inesperado de esta posición, robustamente planteada desde la perspectiva filosófica, sería la que nos lleva a descubrir que su otra cara es la del relativismo, entendido como una de las formas más actuales de escepticismo, que impregna nuestra forma de entender el ámbito de la reflexión estética y moral (cada uno ve una realidad diferente a través del prisma de sus conceptos, cada cultura tiene su propia realidad).

Quizá el mejor modo de expresar lo que comparten realismo metafísico y relativismo, tal y como los hemos caracterizado de manera tentativa, sea una metáfora óptica: imaginemos por un momento que Vicente y Raúl se encontraran en puntos distintos de la ciudad de Cartagena, en concreto que ambos estuvieran en lados distintos del Castillo de San Felipe. Sigamos con el experimento mental y pensemos que desde un lado el Castillo se viera limpio y nuevo, por las reformas, mientras que del otro, se alcanzase a contemplar en su estado menos conservado, debido a que aún no se habrían llevado a cabo las tareas de limpieza y restauración. Si cada uno de nosotros, Vicente y Raúl, dibujase el Castillo ofreceríamos representaciones completamente diferentes del mismo objeto. ¿Pero cómo es posible que existan dos o más representaciones distintas de la misma entidad? La respuesta tendría que ser que existe una representación de ese objeto que integra las representaciones parciales. La idea del realista metafísico es la de que existe una representación del objeto que permite dar cuenta de todas las representaciones parciales de ese mismo objeto.

Fue Bernard Williams, claro, el que introdujo la distinción entre una concepción absoluta de la realidad y la idea de representaciones parciales o locales de la misma (Williams 1996, 82). La concepción absoluta sería la que extrajera aquellas propiedades que el objeto tiene con independencia del contexto, o del punto de vista, y que explicarían las diferentes representaciones. Según Williams, Descartes habría concebido que la ciencia sería la encargada de proporcionar esa concepción absoluta de la realidad.

La pregunta obvia, una vez que queda claro que la ciencia se desarrolla a partir de nuestras propias capacidades epistémicas, y que es posible que haya propiedades del mundo que no estén abiertas a nuestras habilidades cognitivas es, ¿no será la ciencia una representación parcial más, una manera de mirar el mundo? ¿En qué sentido podría ser el punto de vista de ningún lugar?

6 Convencionalmente considerado como el resultado de los argumentos escépticos planteados por Descartes en sus Meditaciones Metafísicas, aunque tal tesis sería discutible (y su crítica escapa a los límites de este texto). 
A esta idea le sigue la tesis del relativista de que el acceso siempre es parcial $\mathrm{y}$, en ese sentido, cabría decir de manera tentativa que hay un suelo compartido entre relativista y realista metafísico: nuestro esquema conceptual sería un velo que distorsionaría nuestro acceso a lo real, pero la realidad estaría allí, con independencia total de lo que nosotros pensásemos de ella.

Sin embargo, cabría decir que el argumento de la representación absoluta de la realidad no podría seguirse de manera consistente hasta el final, ya que desde el punto de vista óptico toda perspectiva es una perspectiva frente a otras, no hay ninguna perspectiva que sea la perspectiva. En ese sentido, para ver cómo se relacionan dos representaciones diferentes se necesita postular una tercera, que integre ambas, no una representación absoluta del objeto. Pero si esto es así, se deduce de ello que no es necesario apelar a una representación absoluta para resolver la relación entre dos representaciones en litigio, que basta con esa tercera que las enlace.

Cuando se plantea el tema del relativismo cultural, o del estético como un capítulo del mismo, se buscan criterios de racionalidad comunes a todas las culturas, para ver si se puede determinar el valor de cierta práctica o creencia perteneciente a una u otra visión del mundo. Tendemos a pensar que de no existir tales criterios universales, todo vale. Aunque, al igual que para dar cuenta de las representaciones parciales no sería necesaria una representación absoluta, para tratar con este tipo de litigios tampoco haría falta disponer de criterios universales de racionalidad.

Para reconocer en otra cultura determinado comportamiento cultural ha de existir algún parecido, alguna intersección entre ambas culturas y la cuestión es que parece que tales intersecciones existen, que las diferentes culturas tienen puntos en común, lo que permite iniciar la discusión acerca de la racionalidad de determinadas creencias ${ }^{7}$. No es necesario, sin embargo, que lo que dos culturas tienen en común sea común a todas las culturas, esto es, que podemos relacionarnos en aspectos y contextos concretos, variables de uno a otro contacto, de una a otra cultura.

Pero, ¿qué relación guarda todo esto con la discusión entre aquellos que no conceden más que un papel muy secundario a la historia, en pro de un supuesto diálogo racional en un espacio problemático universal, y los que apelan a la necesidad del contexto y la reconstrucción hermenéutica como elementos irrenunciables de la actividad y la disciplina filosófica? ¿Qué vínculos guarda lo antedicho con las diferentes concepciones de la relación que existe entre historia y otros ámbitos de la actividad humana, como la ciencia o el arte?

La cuestión sería que frente a la alternativa entre la supuesta búsqueda de verdad no condicionada por la historia, ni por los diversos contextos, del modelo científico, y la atención a la tradición, y el respeto de su rica multiplicidad contextual, del ámbito

7 Podemos reconocer, por ejemplo, determinado ritual como un matrimonio, aunque muchos de sus elementos se nos escapen u otros rituales de esa misma cultura nos sean difíciles o imposibles de entender o reconocer. 
artístico, sería necesario plantear una posición diversa. Se trataría de apelar a la capacidad de la filosofía de percibir aspectos en los distintos contextos y períodos históricos de su tradición, con los que establecer un diálogo, consciente tanto de las semejanzas como de las diferencias. Y lo mismo podríamos decir en el caso de los modelos de relación con la historia propiamente filosóficos, tanto el problemático, con sus aspiraciones de universalidad y actualidad, poco atentas a la historia, como el contextual, quizá excesivamente vinculado a los diferentes períodos históricos como para establecer puentes entre pasado y presente.

La relación entre historia y filosofía, desde la perspectiva planteada por la crítica a las posiciones realista y relativista, no encontraría su guía en el modelo científico, tal y como tópicamente se lo concibe, porque no cabría apelar a una realidad que estaría allí, por detrás de los diferentes puntos de vista y contextos históricos, a una verdad "objetiva" hacia la que se progresaría de manera ineluctable mediante una serie de problemas planteados desde la actualidad. En ese sentido, la concepción de la historia manejada por algunos filósofos seguidores de este modelo, una suerte de historia vindicatoria que apelaría a logros irrefutables, resultaría difícilmente sustentable.

Pero el modelo histórico del arte, tal y como se lo ha concebido habitualmente, tampoco convendría a la actividad filosófica. Y es que aunque los principios que articulan el campo del obrar filosófico tengan ese carácter de legado que también caracteriza a muchos de los motivos y principios ordenadores de la actividad artística, sería cuanto menos difícil comparar la inquietud por la verdad que caracterizaría al filosofar con las búsquedas estéticas que definen al arte. La supuesta imposibilidad de alcanzar criterios universales en el ámbito estético, su incursión en el relativismo en sentido amplio, chocaría con la apuesta racional propia de la indagación filosófica, en todo tiempo y contexto.

Sin embargo, como hemos dicho anteriormente, no estamos plenamente de acuerdo al menos con la imagen tópica del modelo artístico, ya que precisamente su atención a los contextos nos parece que no descuida la búsqueda de sentidos o la percepción de aspectos que se plantea como alternativa al debate entre absolutismo y relativismo, y por ende a la cuestión del modelo de historia más adecuado para la filosofía. Igual que en el campo filosófico hay una búsqueda de soluciones correctas a los problemas que se propone investigar, como pasa en el ámbito científico, en el arte hay búsquedas de sentido relacionadas con la realidad social en la que se arraiga, y en ambos casos la apelación a los contextos no necesariamente ha de conducir al relativismo. La historicidad de las diversas filosofías y de las distintas propuestas estéticas no implica la renuncia a la veracidad de la filosofía, o al sentido en el arte, a la existencia de criterios comunes entre diversos períodos y contextos, aunque no existan criterios universales o realidades "objetivas" como piedra de toque.

En suma, la propuesta de la "historia de los problemas", que pasa por leer a los autores del pasado como si estuviesen escribiendo para responder a nuestras preocupaciones modernas en el ámbito de la filosofía no hace justicia a esos autores. El diálogo racional que caracterizaría a la disciplina filosófica puede ser uno, la filosofía pese a su reciente constitución como disciplina mantendría una unidad clara, pero eso 
no puede excluir las diferencias históricas, las voces y contextos conceptuales distintos y distantes en los que se ha concretado el filosofar. E igualmente, la lectura meramente histórica, la reconstrucción contextual de las diversas filosofías, podría arrojarnos a un relativismo que en última instancia nos arrastraría a la incomprensión y el silencio, a la desconexión entre las diferentes épocas que han configurado nuestra historia, a la pérdida del sentido de aquello que más propiamente parece caracterizar a nuestra actividad: la comprensión del mundo que nos rodea.

Frente a esto, y teniendo en cuenta nuestra propuesta de relectura del modelo del arte, que se mueve en la frágil línea que separa realidad y ficción, que atiende a contextos, pero que no por ello se hunde en un relativismo craso, cabría plantear un modelo de relación con la historia para la filosofía que, sin necesidad de apelar a un esencialismo difícilmente justificable, tampoco redujese el papel de la misma a un mero complemento prescindible.

La filosofía apunta a la verdad pero no lo hace sin prestar atención a los contextos en los que surgieron las diversas propuestas, las distintas filosofías, que querían responder a tal indagación. Leer a los autores del pasado nos permite, en ciertos casos, descubrir que aquello que tomábamos por universal e irrefutable no lo es tanto, y que lo que en primera instancia pudimos entender como errores fruto de la ignorancia de tiempos más oscuros, son en realidad miradas diferentes sobre nuestro mundo común, tan valiosas como las nuestras. Entrar en diálogo con los clásicos nos permite encontrar puntos en común, semejanzas, diversas en cada caso, y al mismo tiempo ser conscientes de la existencia de diferencias y distancias que no pueden salvarse de manera inmediata.

El filósofo tendría así entre sus actividades fundamentales la lectura de los textos del pasado, de las diversas filosofías que integran la filosofía, para ahondar en la comprensión de su búsqueda racional. En este sentido, podría seguir quizá la admonición de Proust en el ámbito literario:

Unas alas, otro aparato respiratorio, que nos permitieran atravesar la inmensidad no nos servirían de nada, pues trasladándonos a Marte o Venus con los mismos sentidos, darían a lo que podríamos ver el mismo aspecto de las cosas de la tierra. El único viaje verdadero, el único baño de juventud, no sería ir hacia nuevos paisajes, sino tener otros ojos, ver el universo con los ojos de otro, de otros cien, ver los cien universos que cada uno de ellos ve, que cada uno de ellos es; y esto podemos hacerlo con un Elstir, con un Vinteuil, con sus semejantes, volamos verdaderamente de estrella en estrella (Proust 1987-89, III, 762).

Si la historia no tuviese ningún peso en la filosofía, si los problemas fuesen inalterables en el curso del tiempo, leer a Platón o a Descartes solo serviría para confirmar lo ya sabido. Que esto no sea así, que no sea posible sin someter a una deformación injustificable a los autores clásicos, y que los diversos contextos histórico-filosóficos tengan peso en nuestra disciplina, no implica renunciar a la unidad de la misma, ni perderse en los extremos del relativismo o de lo anacrónico. La filosofía integra en su historia diversas filosofías en un diálogo racional en el que tanto las semejanzas como las diferencias tienen un peso, y en donde las variaciones en las distintas representaciones del mundo contribuyen a iluminar un espacio común, un mundo compartido. 


\section{Referencias bibliográficas}

Descartes, René (2005), Meditaciones metafisicas con objeciones y respuestas. Oviedo: KRK. (1987), Discurso del método. Madrid: Tecnos.

Engel, Pascal (1999), "Retour aval”, Les etudes philosophiques 4: 453-463.

González, María Cristina y Stigol, Nora (2012), "La filosofía y su historia. Un debate abierto", Revista de filosofía 37/2: 151-170.

Hegel, Georg Wilhelm Friedrich (2010), Fenomenología del espiritu. Valencia: Pretextos.

Hume, David (2001), Investigación sobre el conocimiento humano. Madrid: Alianza.

Jaran, François (2011), "Cómo la tradición continental y la tradición analítica se enfrentan con la tradición filosófica", Revista de filosofía 36/1:171-192.

Jusdanis, Gregory (2014), Los adversarios de la ficción. Cartagena: Editorial Universitaria - Universidad de Cartagena.

MacIntyre, Alasdair (1990), "La relación de la filosofía con su pasado", en R. Rorty, J. B. Schneewind y Q. Skinner, eds., La filosofia en la historia. Ensayos de historiografía de la filosofía. Barcelona: Paidós, 49-67.

Paganini, Gianni (2008), Skepsis. Le débat des modernes sur le scepticisme. Paris: Vrin.

Passmore, John (1965), “The Idea of a History of Philosophy”, History and Theory 5: $1-32$.

Proust, Marcel (1987-89), En busca del tiempo perdido, vol. III. Madrid: Alianza.

Skinner, Quentin (1969), "Meaning and Understanding in the History of Ideas", History and Theory 8: 3-53.

Taylor, Charles (1990), "La filosofía y su historia", en R. Rorty, J. B. Schneewind y Q. Skinner, eds., La filosofia en la historia. Ensayos de historiografia de la filosofía. Barcelona: Paidós, 31-47.

Williams, Bernard (2011), La filosofia como una disciplina humanística. México: FCE.

(2002), "Why Philosophy needs History?", London Review of Books. Oct.: 7-9.

496.

(2000), "Philosophy as a Humanistic Discipline", Philosophy 75: 477-

(1996), Descartes: El proyecto de la investigación pura. Madrid: Cátedra.

Windelband, Wilhelm (1980), Lehrbuch der Geschichte der Philosophie. Tübingen: Mohr Siebeck. 